\title{
Future Visions of Technology-Enhanced Professional Learning
}

\author{
Kamtsiou, V. ${ }^{1}$, Naeve, A. ${ }^{2}$, Stergioulas, L. K. ${ }^{3}$ and Pappa, D. ${ }^{1}$ \\ ${ }^{1}$ Division of Applied Technologies, National Centre for Scientific Research -Demokritos, Athens, Greece. E-mail: \\ \{vana; dimitra\}@dat.demokritos.gr \\ ${ }^{2}$ Royal Institute of Technology (KTH), NADA, 10044 Stockholm, Sweden, Sweden. E-mail: amb@nada.kth.se \\ ${ }^{3}$ Department of Information Systems and Computing, Brunel University, Kingston Lane, Uxbridge, Middlesex UB8 \\ 3PH, UK. E-mail: Lampros.Stergioulas@brunel.ac.uk
}

\begin{abstract}
The paper presents the future visions of technologyenhanced professional training as expressed in a pan European roadmapping activity. The paper introduces a new approach to developing a roadmap for technology-enhanced professional training. Interesting findings from the first phase, which identified the future visions are presented and their analysis using conceptual, mapping is proposed.
\end{abstract}

\section{Introduction}

The aim of this foresight study is to map out the desired future for technology-enhanced professional learning (TEPL) in the form of prevalent visions in the community at large. The study represents the first phase of a larger technology roadmapping activity aiming to provide a 10-year-span technology roadmap for European professional training, an initiative which has been launched within the PROLEARN Network of Excellence. [22]

The PROLEARN Network of Excellence focuses on identifying the emerging future e-Learning scenarios and contexts, in the form of future technologyenhanced professional learning resources, and the use of these learning resources for professional training in Small/Medium Enterprises (SMEs) and larger companies. In pursuing this, the PROLEARN Network of Excellence aims to also advance the state-of-the-art in the critical areas of personalized adaptive learning and interactive media, with learning resources connected to real-world settings and reusable in different contexts.

This paper first describes in detail the specific methodology employed in order to compile a roadmap for professional technology-enhanced professional training for the mid-term future (the following 10 years). It then follows on to describe the work of the first phase (vision foresight) and discusses preliminary results. The work has brought together external experts and industry stakeholders in order to synthesize and combine knowledge.

\section{The roadmapping processes}

The PROLEARN roadmapping process aims to provide us with the information of where we are (current state) and were we want to go (vision/foresight/desired future). Once this is achieved we will be in a position to determine how we can get there (action plan). The process includes the following stages. (Figure 1)

Vision: tacit idea representing the desired future state Expressed future state: instantiation of the vision in a formal and systematic way

Gap analysis: between the current state of the art and desired future state (critical capabilities needed to implement one or more vision statements)

Actions: a portfolio of short-, mid- and long-term actions and recommendations, based on the gap analysis

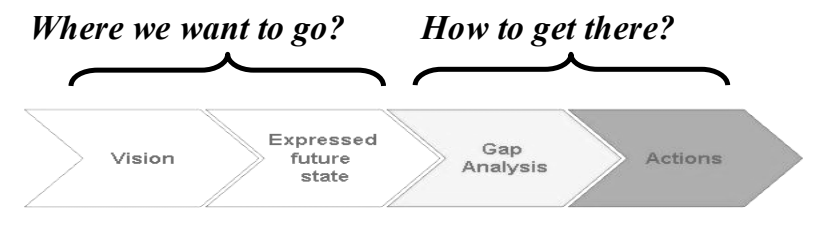

Figure 1. Roadmapping stages

In Figure 1, the first two stages comprise Phase 1 (Where do we want to go? - outputs: Vision statements and Expressed future state) and the last two stages comprise Phase 2 (How can we get there? - outputs: Critical capabilities and Recommended actions).

This paper is concerned with the formulation of the future visions (Phase 1). In Phase 1, the future scenarios and the shared visions are identified and 
effectively the framework is set up for the subsequent gap analysis. A variety of activities, including scenario building, international forums, surveys and workshops with experts, are used to derive and express the visions, in terms of the core concepts (vision statements, goals and influential factors). The main principle is "finding the currents that lead you where you want to go" (proactive), instead of "floating in the currents you are presently in" (reactive).

In the framework of PROLEARN, roadmapping is a knowledge creating process (figure 2) that spirals outwards from the core partners of the PROLEARN Network (individuals, groups, the whole Network) via the Network's associated partners, to the entire scientific community and industry. Therefore, it is both a learning activity and a knowledge creation process for the community that builds the roadmap. According to Nonaka [12-16], the key to knowledge creation lies in the following four SECI modes of knowledge conversion, which occur when tacit knowledge and explicit knowledge interact with each other:

- Socialization (sharing tacit knowledge): The process of sharing experiences (tacit knowledge), thereby creating new tacit knowledge.

- Externalization (converting tacit knowledge into explicit knowledge): The process of articulation and conversion of tacit knowledge into explicit knowledge.

- Combination (Systematic combining of explicit knowledge): The process of restructuring and aggregating explicit knowledge into new explicit knowledge.

- Internalization (Internalizing new knowledge as tacit knowledge by the organization): The process of reflecting on explicit knowledge and embodying explicit knowledge into tacit knowledge.

According to Nonaka, because tacit knowledge includes mental models and beliefs in addition to know-how, moving from tacit to the explicit is really a process of articulating one's vision of the world - what it is and what it ought to be. When individuals invent new knowledge, they are also reinventing themselves, their organization and even the world. [12-16]

Similarly, knowledge creation in a roadmapping exercise is a continuous process where individuals and groups transcend their boundaries by acquiring a new context, a new view of the subject domain, and new knowledge. The employed roadmapping process model (Figure 2) is derived from the SECI process by replacing the triplet of social entities \{Individual, Group, and Organization\} with \{Core Partners, Associate Partners, and Scientific Community \& Industry $\}[2,8]$

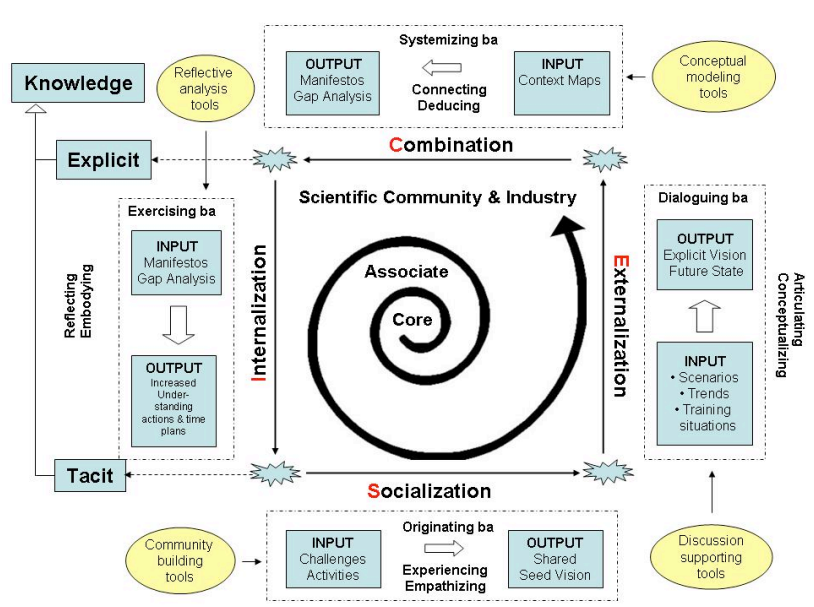

Figure 2. The PROLEARN roadmapping process Framework (based on SECI model)

During the Socialization process, networking activities and community building tools are important. Face to face meetings, various workshops, and virtual meetings were organized to bring together the wider community of the PROLEARN network (both core and associate partners spanning more than 300 organizations) on a common contextual platform and tap into their collective experience and knowledge.

During the Externalization process, awareness was raised of the key issues involved in TEPL, and the implicit concepts and ideas originated during the socialization process were expressed. Individual views and visions were expressed via scenarios produced by PROLEARN partners, and by other experts and initiatives, and also through brainstorming sessions where individual visions were discussed and extended. These activities provided with a good indication of what TEPL means for different stakeholders in a variety of Professional situations. Desktop research and online surveys are also used during this phase. The aim was to create seed visions that can be used as input for starting a dialogue with external groups. The next step was to initiate a dialogue with external experts and industry stakeholders in order to synthesize and combine knowledge. In this activity, it is important to bring together people with different expertise and scientific backgrounds. A symposium with researchers, academics, industry experts and policy makers was organized where the seed visions were discussed and extended by others. Interviews with companies, forums and virtual communities are also set up in order to test, validate and update the vision statements.

During the Combination process, the outcomes of the dialogues are analyzed in order to clearly systematize 
concepts, identify trends and factors influencing those concepts and analyze their relationships. During this phase we use conceptual modeling tools. The different context maps are studied and the final vision statements are derived. The resulting knowledge is formulated and presented using the Conzilla browser tool.

During internalization process, this explicit knowledge, in turn, can be reflected upon and internalized into new tacit knowledge

In the later Phase 2, the critical elements for achieving the vision statements will be identified and a gap analysis of what is available and what is missing (needed for the future) will be performed.

PROLEARN roadmapping is not a linear process and more cycles of the SECI Spiral will follow. Figure 3 provides a more in depth view of the spiraling "express future state" process which transcends individual views and experiences to form collective knowledge at a macro level (definition of desired future state - shared vision).

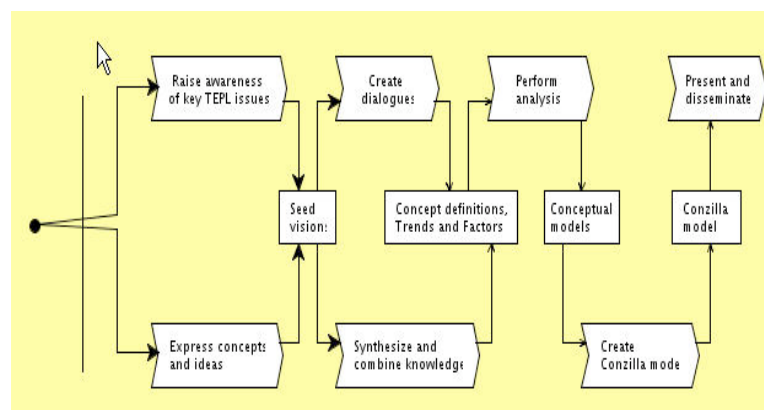

Figure 3: Express future state

Prolearn teams (WPs), play a central role in this knowledge creation process of building the roadmap because they provide the shared context where the team members can interact with each other and engage themselves in common projects and activities on which effective reflection depends. This provides a new individual understanding of the relevant concepts and their relationships. This new "know-how" is articulated via a constant dialogue where teams pool their information and examine it form different angles, thus integrate their diverse individual perspectives into a new collective perspective. The resulted "seed" knowledge is modeled and conceptualized and thus is easily communicated to external groups in order to synthesize information from many different sources and bring in different perspectives and contexts. In that way, an increased collective understanding is achieved where the actual concepts and their contexts are reinvented and extended by others. To this end, the micro and macro dimensions interact with each other, and changes occur at both the micro and the macro level. Thus the existing visions of the core partners of the PROLEARN network (micro) influence and at the same time are influenced by the environment (macro) with which the network interacts.

\section{Formulation of Visions}

Initial findings included both the identification of major trends and the articulation of vision statements for the desired future state. A number of instruments have been employed to identify major trends and derive vision statements from stakeholders, including: International Roadmapping forums; Interviews with companies (to generate discussion on the vision statements); Virtual communities on the web and multi-target large scale online survey on trends.

\subsection{Scenario Analysis}

In order to draw the roadmap between the current state $(A s-I s)$ and the desired future state $(T o-B e)$, detailed possible future scenarios were developed. The training solutions described in the scenarios represent realistic everyday training in ten years from now in various professional situations. Twenty five scenarios were processed and analyzed and the key drivers and factors per scenario were identified. During the scenario analysis process, we have described the primary focus of each scenario as the scenario training context, the business requirements as the driving forces behind the scenario, and the focus areas, where the focus should be if one wanted to realize the scenario. The sources for the 25 scenarios were the following: 11 scenarios have been independently developed by Prolearn core and associated partners, 7 scenarios were analyzed from the work of Norris et al. [17]; Time2Learn Thematic Network (EU): 1 scenario; ROCKET project (EU): 2 scenarios; Ariel Project (EU): 4 scenarios.

Analyzing the scenarios, we start from identifying the key business requirements which are considered to be the driving force behind the scenarios. The rationale behind these groups of drivers is primarily economic, centered on the use of TEPL in order to improve competitiveness in EU companies. Four different sets of business requirements have been identified. Each set has a different focus. The first 3 sets are more focused on the intrinsic business requirements and are differentiated by the intended result of the training: a) 
TEPL supporting Continuous Improvement in Companies (micro level); b) TEPL supporting Business Process Re-engineering in Companies (medium level); c) TEPL supporting Goal Oriented Change in Companies (macro level). The 4th set is focused more on the market requirements and the emergence of knowledge exchanges and new ways of knowledge management. The next step was to identify the main priority areas where most of the new challenges are found: the technology area and the socio-cultural area.

Technology Area: Knowledge markets; Content Development, management and delivery (anytime, anywhere); Processes, models and infrastructures; "Ambient Intelligence".

Socio Cultural Area: Collaboration \& Communities of Practice; Informal learning, capture and exchange of tacit knowledge; New University structures (i.e. Corporate University); Universities as providers of learning services adapted to corporate needs; Associations (Professional, Trade Unions) offer access to experts and communities of practice.

\subsection{Core vision for TEPL in 2015}

The PROLEARN Summer School Roadmapping Workshop [24] integrated the results from previous PROLEARN foresight activities and came up with the following core vision the future TEPL: “To support knowledge workers with technology-enhanced learning by promoting motivation, performance, collaboration, innovation and commitment to lifelong learning." In this context, a knowledge worker is defined as someone who doesn't just consume knowledge but who is able to create it and who reflects critically on every level of activity in the organization and contributes back.

\subsection{The six vision statements}

The Core vision is broken into 6 individual vision statements that synthesize and explain the core vision. Each vision statement has its distinct overall perspectives and focus.

Vision statement I: "Everyone should be able to learn anything at anytime at anyplace." The goal is to deliver the right content at the right time for the right person. The new capabilities offered by recent advances in internet and mobile communications, can support and facilitate mobility towards a life-long learning environment, enabling the creation, storage, management and access to knowledge anywhere and anytime.
Vision statement II: "Learning as a means to support and enhance work performance." The main goals are to support performance improvements, business process re-engineering and the development of competencies, engineer a shift towards performance driven processes, and provide links between business processes and learning processes. Use TEPL to design high quality work-based learning activities so that learning and working becomes interlocked.

Vision statement III: "Promote innovation and creativity (entrepreneurship) versus task- and business process-oriented learning." This vision encompasses a variety of goals such as: Goal oriented Changes at strategic level, develope meta-competences (i.e. thinking out of the box, creativity, asking the right questions, leadership), Human Capital Growth, promote entrepreneurship, cultivate and externalize tacit knowledge, encourage Knowledge sharing.

Vision statement IV: "Learning as a means to increase employability." The goals in this vision include resilience, employability, become skilled faster and personal growth. This statement is focuses on Learner's Perspective, the employees' continuous professional development, and the need to increase employability.

Vision statement V: Market take-up. "Professional elearning will be a commodity market in 2015." Goals and challenges in this vision include market transparency, consumer driven market, one-stopshopping, wider choice at all levels, and selection optimization. Development of both segments of the market: from the low end commodity market to the high end upscale, high value added segment. This statement focuses on market take up of TEPL and the ability to purchase content and learning services regardless of type and country of the learner supplier in a unified transparent market.

Vision statement VI: "High quality learning at the workplace for all - An Information society for all". The goal/challenge will be to democratize knowledge Provision and effect the so-called e-Inclusion and equal opportunities for all in the workplace. This statement addresses social inclusion issues, such as digital divine, the gap between poor and rich etc.

\section{Findings of the European Experts' Symposium on Future and Emerging Issues in TEPL}

The objectives of this symposium [1] were to identify, record, discuss and analyze the emerging issues of technology enhanced professional learning and to pave the way for common future actions. The symposium had a unique focus on the future of technology 
enhanced professional learning and was a two-dayevent involving 67 distinguished experts representing various sectors of the European Education and Training Community. The dialogue resulted in the articulation of the following interesting points:

- The vision for the future Knowledge Workers focuses on three main axes:

- promotion of innovation, creativity, proficiency and flexibility in learning and work,

- maximum employability of the European labor force, and

$\circ$ equal opportunities in education and career.

- The management of human resources has to change and learning has to be integrated in the working and business processes.

- Time-to-proficiency becomes increasingly important in order for the European companies to stay competitive. Therefore, there is a need to improve the conditions for individual and organizational learning significantly and systematically in order to increase the learning speed and the ability of individual workers as well as companies to change rapidly.

- The training programmes have to be aligned with the strategic goals of the enterprise

- A tendency of convergence between work and personal life is observed, where the lines between learning and work, work and leisure, and also formal, informal, non formal forms of learning, are becoming more and more blurred.

- The need of greater flexibility in professional development is a stress-inducing factor for the employees, as it creates intense feelings of insecurity towards work.

- Greater understanding is needed on what the knowledge worker needs are and what the skills and competencies in the new knowledge society and knowledge work should be. There is also a need to identify the underlying factors that have a major impact on knowledge worker productivity, some of them being very difficult to measure, such as values, self-image, traits and motives.

- An important change relating to the organization of jobs and company structures is emerging, which tends towards the demise of hierarchy as well as of specific titles and job descriptions, with a strong tendency towards flexible types of jobs defined by the particular "projects".

- An increased imbalance of education was identified between higher ranked and lower ranked employees, as well as between small and large enterprises. In reality, "the future is already here but unequally distributed".
- The most-likely-to-succeed future type of training will be the "personalized learning", which offers to the specific person the right skills, at the right time within the specific context (work, social, technical, cognitive etc).

- We also observe an increasing convergence between official and unofficial training

The Athens High-Level Symposium with International Experts [1] refined the output and articulated an overarching, condensed statement of the Future Vision, emphasizing "the promotion of innovation, creativity, flexibility in learning and work, employability, and equal opportunities".

\section{Conceptual model of the roadmapping process}

In order to develop a value accumulating, ongoing roadmapping process with a high potential for sustainability, PROLEARN employs modeling techniques to identify the essential concepts and their complex relationships in various contexts and to visualize them in a way that can be communicated to end extended by various stakeholder groups. A conceptual model of the roadmapping process has been developed. For this purpose the Conzilla concept browser was adapted for roadmapping process modeling and a first version is already available. $[7,9,10]$. This model is an "electronic document" in the form of a Java applet, which is available at www.conzilla.org/demo/RM.html

\section{Conclusion}

Recent findings from a pan-European roadmapping exercise on the future of technology-enhanced professional training have been presented in terms of visions describing the desired future state. The study employs a new approach to roadmapping and the task of identifying the prevalent future visions involved a series of consensus building activities including scenario building and community-based surveys and forums. The prevalent visions for the next 10 years seem to be centered on leveraging technology to promote (a) high performance for businesses through innovation, creativity, and flexibility, and (b) increased security for individuals in the form of employability and assuredness of equal opportunity.

\section{References}


[1] High-Level Symposium with International Experts on Technology Enhanced Professional Learning - Athens 19 and 20 December 2005.

[2] Kamtsiou, V., et. al. (2005) Roadmapping Methodology and Framework Analysis, version 2, Prolearn Deliverable 12.6, June June 2005.

[3] Kamtsiou, V., Stergioulas, L. K., Koskinen, T. (2005) A roadmapping framework for technologyenhanced professional training, Proceedings of the 8th IFIP World Conference on Computers in Education (WCCE 2005), Cape Town, South Africa, 4-7 July 2005, pp. 157-166.

[4] Kappel, Th. (2001) Perspectives on roadmaps: how organizations talk about the future. The Journal of Product Innovation Management, Vol. 18.

[5] Lytras, M., Naeve, A., Pouloudi, A. (2005) A Knowledge Management Roadmap for E-Learning: The Way Ahead, International Journal of Distance Education Technologies, Vol. 3, No. 2, pp. 68-75, (Special Issue on Knowledge management Technologies for E-Learning), April-June 2005.

[6] Naeve, A. (2001a) The Knowledge Manifold - an educational architecture that Supports Inquiry-Based Customizable Forms of E-learning, Proc. of the 2nd European Web-based Learning Environments Conference (WBLE 2001), pp. 200-212, Lund, Oct. 24-26, 2001 http://kmr.nada.kth.se/papers/KnowledgeManifolds/Knowled geManifold.pdf.

[7] Naeve, A. (2001b) The Concept Browser - a New Form of Knowledge Management Tool, Proc. of the 2nd European Web-Based Learning Environment conference, pp. 151-161, Lund, Sweden, October 24-26, 2001, http://kmr.nada.kth.se/papers/ConceptualBrowsing/ConceptB rowser.pdf.

[8] Naeve, A., Yli-Luoma, P., Kravcik, M., Lytras, M., Simon, B., Lindegren, M., Nilsson, M., Palmér, M., Korfiatis, N., Wild, F., Wessblad, R., Kamtsiou, V., Pappa, D., Kieslinger, B. (2005). A Conceptual Modelling Approach to Studying the Learning Process - with a Special Focus on Knowledge Creation. Deliverable 5.3 of the Prolearn EU/FP6 Network of Excellence, IST 507310, June 2005

[9] Naeve, A. (2005), The Human Semantic Web - Shifting from Knowledge Push to Knowledge Pull, International Journal of Semantic Web and Information Systems (IJSWIS), Vol. 1, No. 3, pp. 1-30, July- September 2005.

[10] Naeve, A., Nilsson, M., Palmér, M. (2001) The Conceptual Web - our research vision, Proceedings of the first Semantic Web Working Symposium, Stanford, July 2001, www.semanticweb.org/SWWS/program/position/soinilsson.pdf

[11] Naumanen, M. (2001) Roadmap - Kartta menestykseen. In MET-julkaisuja nro 23/2001, Finland.

[12] Nonaka, I. (1994) A dynamic theory of organizational knowledge creation, Organization Science, Vol. 5, No. 1, pp. 14-37.

[13] Nonaka, I., Takeuchi, H. (1995) The knowledge-creating company: How Japanese companies create the dynamics of innovation, New York: Oxford University Press.

[14] Nonaka, I. and Toyama, R. (2003) The knowledgecreating theory revisited: knowledge creation as a synthesizing process, Knowledge Management Research \& Practice, Vol. 1, No.1, pp2-10
[15] Nonaka, I., Konno, N., The concept of "Ba": Building foundation for knowledge creation. California Management Review Vol 40, No.3Srping 1998.

[16] Nonaka, I., Toyama, R., Konno, N. (2000) SECI, Ba and Leadership: a Unified Model of Dynamic Knowledge Creation, Long Range Planning, Vol 33 (2000), Elsevier Science Ltd.

[17] Norris, D., Mason, J., Lefrère, P., (2003).Transforming e-knowledge, 2003.

[18] Novak, J. D. (1990) Concept maps and Vee diagrams: Two metacognitive tools for science and mathematics education, Instructional Science, 19, 29-52.

[19] Novak, J. D. (1991) Clarity with concept maps, The science teacher 58(7), pp. 45-49.

[20] Novak, J. D. The Theory Underlying Concept Maps and How To Construct http://cmap.coginst.uwf.edu/info/printer.html

[21] Palmér, M., Naeve, A. (2005) Conzilla - a Conceptual Interface to the Semantic Web, Invited paper at the 13:th International Conference on Conceptual Structures, Kassel, July 18-22, 2005. To be published in the series of Springer Lecture Notes on Computer Science.

[22] PROLEARN Network of Excellence, http://www.prolearn-project.org

[23] PROLEARN network (2004) Roadmap methodology and framework analysis, Deliverable D12.1.2, IST

[24] ROLEARN Summer School Roadmapping Workshop at the PROLEARN Summer School, Istanbul, Turkey, 5-9 September 2005.

[25] Probert, D., Radnor, M. (2003) Frontier Experiences from Industry-Academia Consortia, Research Technology Management, Vol. 46, No. 2.

[26] ROCKET project (2002) The state -of-the-art of Roadmapping, Deliverable D2.2, IST-2001-38245 ROCKET project (Roadmap to communicating knowledge essential for the industrial environment).

[27] Rumbaugh, J., Jacobson, I., Booch, G. (1999) The Unified Modeling Language Reference Manual, Addison Wesley Longman Inc.

[28] Rehak, D. (2003), A SCORM Roadmap: SCORM's Technical Evolution, $\mathrm{http}: / / w w w .1 s a l . c m u . e d u / l s a l / e x p e r t i s e /$ papers/presentations/p f8roadmap2003/roadmap20031028.pdf

[29] Takeuchi, H., Nonaka, I., (eds) (2004) Hitotsubashi on Knowledge Management, Wiley \& Sons, 2004.

[30] Time2Learn network (2004) Needs assessment for future professional training in Europe, Deliverable D2-2, IST IST Time2Learn Thematic Network, http://www.time2learn.org 